\title{
Development of a Low-Cost SIA-Based Analyser for Water Samples
}

\author{
Moisés Knochen, ${ }^{1}$ Alejandro Caamaño, ${ }^{1}$ and Heinkel Bentos ${ }^{2}$ \\ ${ }^{1}$ DEC, Analytical Chemistry, School of Chemistry, University of the Republic (UdelaR), Avenue Gral.Flores 2124, \\ 11800 Montevideo, Uruguay \\ ${ }^{2}$ DETEMA, Instruments Workshop, School of Chemistry, University of the Republic (UdelaR), Avenue Gral.Flores 2124, \\ 11800 Montevideo, Uruguay \\ Correspondence should be addressed to Moisés Knochen, mknochen@fq.edu.uy
}

Received 30 March 2011; Accepted 24 May 2011

Academic Editor: Miren Lopez de Alda

Copyright () 2011 Moisés Knochen et al. This is an open access article distributed under the Creative Commons Attribution License, which permits unrestricted use, distribution, and reproduction in any medium, provided the original work is properly cited.

\begin{abstract}
An automated multiparametric water analyser was developed and evaluated. The system was based on Sequential Injection Analysis and featured a photometric detection system comprising a tricolour RGB LED source and a photodiode. A program compiled in Visual Basic was used to control the SIA flow system, the LEDs, and the data acquisition and processing. The program loads and executes methods written in ASCII and stored as text files. The system was capable of handling up to four methods simultaneously. When used to carry out methods based on the APHA standard methods, the figures of merit obtained were considered satisfactory for the purpose. The total cost was under US \$4600. It was concluded that the analyser is appropriate for routine use and has potential for an increased number of simultaneous methods and for enhanced capabilities if new versions of the software are developed.
\end{abstract}

\section{Introduction}

Laboratories dedicated to the analysis of water samples currently face an increasing workload. Major concerns exist about the quality of water for such uses as human consumption and crop irrigation. Thus, the number of samples as well as of analytes (both normal components and pollutants) increases continuously, challenging the capacity of analytical laboratories.

In Uruguay, the School of Chemistry of the Universidad de la República has been engaged in water analysis due to an agreement with the Uruguayan water regulatory body (URSEA, Unidad Reguladora de Servicios de Energía y Agua) with the School acting as a contract laboratory for the analysis of water samples from the public water supply. Samples are collected on a regular basis from hundreds of sampling points throughout the country and analysed for almost 60 analytes both organic and inorganic, as well as turbidity, $\mathrm{pH}$, and microbiological parameters. With the exception of a few determinations made on the field, the determinations are carried out in the School's laboratories by means of APHA standard methods [1]. With regard to the inorganic analytes, this means that a large amount of volumetric, colorimetric, and spectrometric determinations are carried out manually, thus presenting a heavy workload for the analysts and resulting in a low throughput.

With the goal of solving this problem, the development of an automatic analyser was proposed. Although commercial automatic analysers for water samples are available, they are expensive. Working in a university environment, it makes sense to engage in the design of the analyser as students, both graduate and nongraduate, can take part in the task. Automation of the analysis of water samples has been the subject of a significant number of papers published in the last years. Many of these works resort to some kind of flow-based technique [2-4]. However, most of the flow-based analysers proposed in the literature are dedicated systems focusing on the determination of one or two parameters in water samples [5-8], mainly for oceanographic research. Less frequent are those presenting the development of a multiparametric 


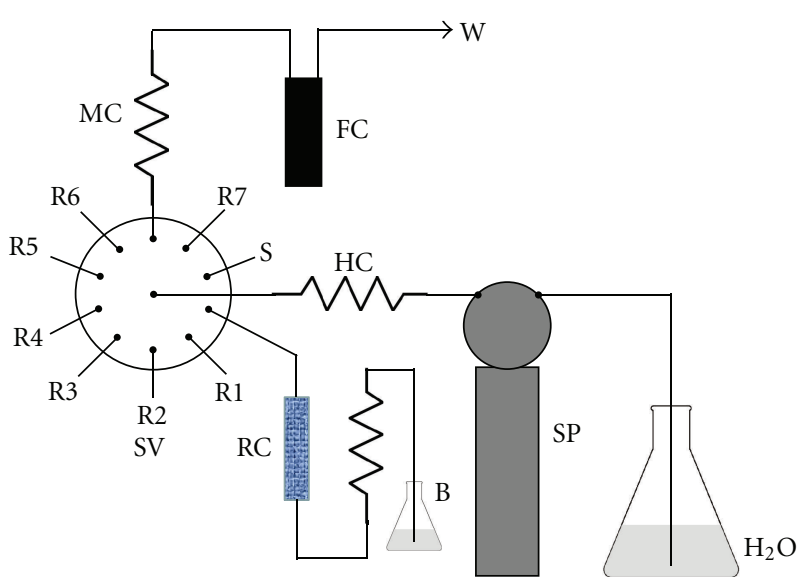

FIGURE 1: flow system. SV: selector valve; SP: syringe pump; FC: flow cell; MC: mixing coil; HC: holding coil; RC: reduction column; S: sample; R1-R7: reagents; W: waste; B: buffer.

analyser [9]. Recently, the concept of a computer supported system of networked automated water analysers has been introduced, the European AWACSS system [10,11] being an example of a continent-wide network of analysers.

Sequential Injection Analysis (SIA) [12,13] was proposed in 1990 as a flow-technique oriented to process analysis but presenting some properties which make it increasingly interesting for the automated routine analysis of water samples. The technique is robust, highly versatile and features lowreagent consumption, resulting in a low volume of chemical residues. Thus, it was decided that the analyser to be designed should be based on this technique. The analyser should have multiparametric capability, that is, it should be capable of carrying out not less than three methods without the need of physical modification or reagent changes. It should also be flexible, allowing a fast and easy change of the analytes and methods under software control, and should be capable of interaction with an autosampler. In order to accommodate the analytical methods currently in use, the proposed analyser should resort to photometric detection based on a multiwavelength light-emitting diode (LED) [14] light source. This light source has been extensively investigated and found to be suitable for low cost and portable analytical equipment [15-20].

This work presents the design, construction, and evaluation of an automatic multiparametric analyser based on SIA for the analysis of drinking and surface water as well as groundwater samples.

\section{Experimental}

2.1. System. The SIA flow system (Figure 1) was based on a syringe pump (Cavro XP-3000, Tecan, Männedorf, Switzerland) with a two-position valve and a $2.5 \mathrm{~mL}$ barrel, and a 10-position Cheminert selector valve with microelectric actuator (Valco Instruments, Houston, Tex, USA, model C25-3180EMH). Each of these devices was fed by its own dedicated $24 \mathrm{~V}$ DC power supply.
Both the pump and the syringe were controlled from a notebook computer via the RS232 serial ports of the devices. Since the notebook did not have any conventional serial port, commercial plug-and-play USB-serial adapters were used to connect the notebook to the pump and the valve, thus generating virtual COM1 and COM2 serial ports.

Connections and coils of the flow system were made with $0.8 \mathrm{~mm}$ (internal diameter) FEP tubing.

A photometric detector was built around a glass flow cell (optical path $10 \mathrm{~mm}$, internal volume $200 \mu \mathrm{L}$ ), a photodiode detector (VTB1013, PerkinElmer), and a common-anode tricolour high-brightness LED (RL5-RGB, SuperBrightLEDs, St. Louis, Mo, USA). The signal from the photodiode was processed by an amplifier implemented with two TL-081 operational amplifiers, and then sent to a 14-bit analogue to digital (A/D) interface (USB-1408FS, Measurement Computing, Norton, Mass, USA) controlled via a USB port of the computer.

Each component of the RGB tricolour LED (red, green, blue, nominal wavelengths $630 \mathrm{~nm}, 525 \mathrm{~nm}$, and $472 \mathrm{~nm}$ ) was driven by a LM-334 constant-current source, in turn fed by one section of a LN-2803 octal Darlington driver IC. The 3 relevant input gates of this driver were controlled from TTL-level signals from the input/output (I/O) ports of the A/D interface. In this way, each section of the LED array could be turned on or off at will, allowing selective use of the LED with the appropriate wavelength under computer control.

A regulated power supply employing LM317 and LM337 voltage regulators provided $\pm 12 \mathrm{~V}$ for the operational amplifiers and LEDs. Figure 2 shows the overall connections and signal paths.

The prototype was built in an industrial plastic box with a hinged lid, measuring $31 \times 30 \times 19 \mathrm{~cm}(W * D * H)$ (Figure 3). The front of the syringe pump and the stator of the valve protrude via holes in the case, thus being accessible for fluidic connections and inspection. The detector flow cell is the only component of the flow path situated inside the case. Two Teflon bulkhead connectors (Omnifit, Cambridge, UK) allow input and output connections to the cell.

A program was written and compiled in Visual Basic 6.0 (Microsoft). A graphic language programming add-on (Softwire 3.1, Softwire Technology) was used together with Visual Basic to allow an easier programming from a graphic environment.

The program controlled the whole operation of the system including the data acquisition, as discussed below. The data (series of absorbance data points) obtained were stored on hard disk as ASCII files.

These data files were later processed with the Peak Simple program (SRI, Torrance, Calif, USA) which provided baseline correction, peak-height measurement, and hard copy printout.

2.2. Reagents. All reagents were of analytical reagent grade. ASTM Type I water was obtained from a Millipore (São Paulo, Brazil) Direct-Q5 water purifier. 


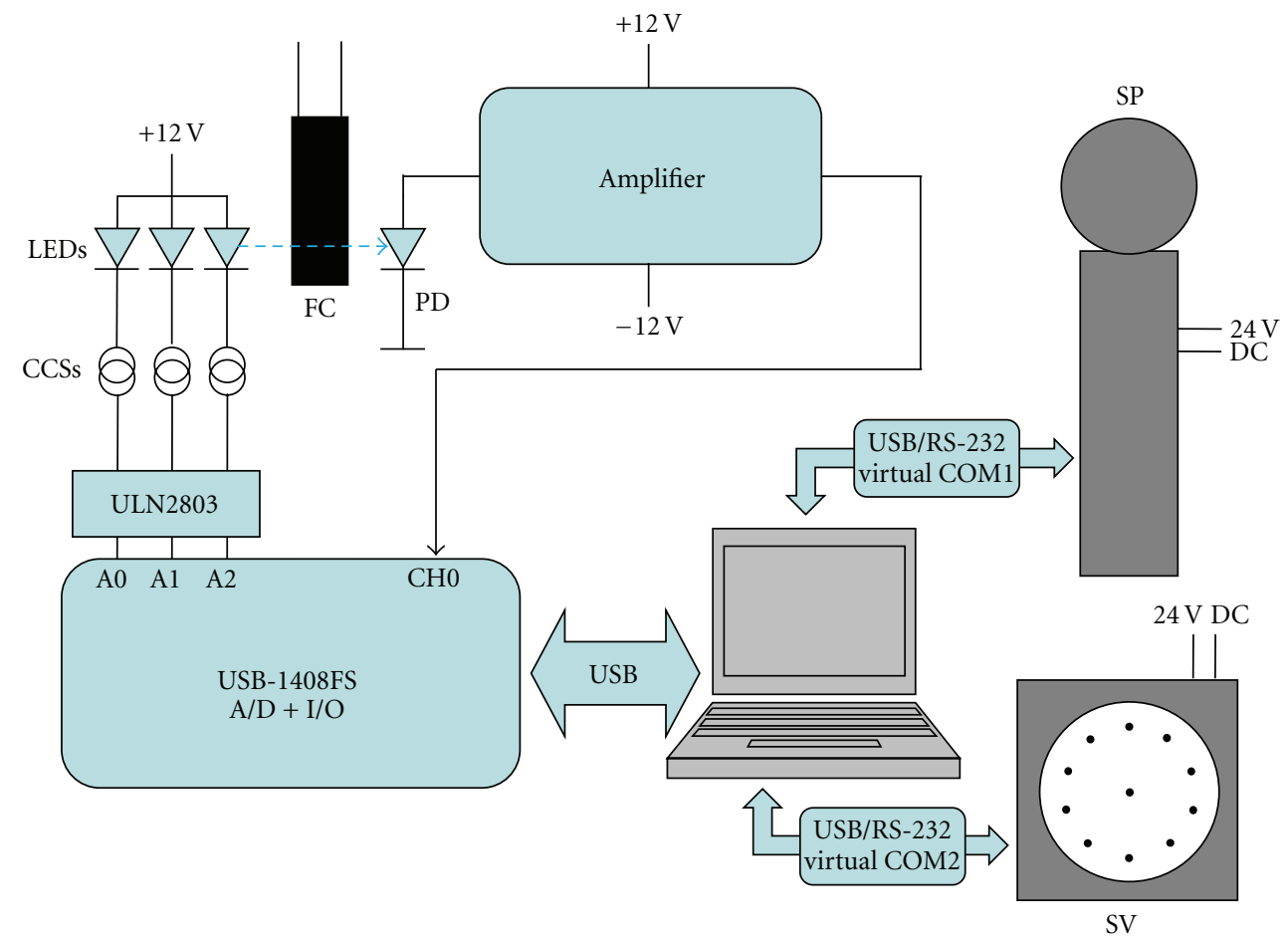

FIGURE 2: Electrical connections and signal paths. LEDs: red, green, blue, light-emitting diodes; CCSs: constant current sources (LM334); USB: universal serial bus connections; SP: syringe pump; SV: selector valve; FC: flow cell.

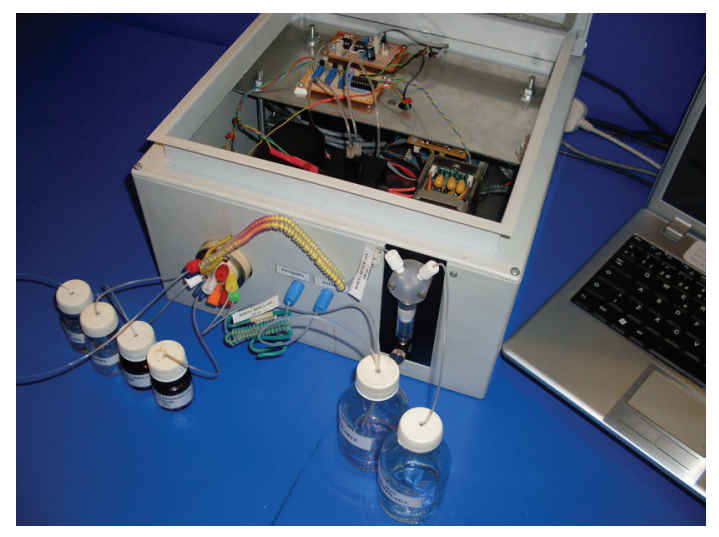

FIGURE 3: Image of the analyser in operation with the top lid open.

\section{Results and Discussion}

3.1. System Development. As schematised in Figures 1 and 2, the prototype of the analyser basically consists of the following sections:

(i) the flow system comprising the syringe pump, the selector valve, and the flow cell;

(ii) the light source and its control unit composed by the tricolour LED, three adjustable constant-current sources and the ULN-2803 driver;

(iii) the photo detector and its amplifier; (iv) a power supply for the analogue portion (amplifier, photodetector, and LEDs);

(v) the A/D interface and its associated TTL I/O ports;

(vi) the notebook computer, with Windows XP operating system, and the USB-serial adapters;

(vii) the custom-written software.

For fluid handling, the use of off-the-shelf components was decided. A syringe pump was chosen as propulsion device because of its high reliability. The Cavro pump not only can be easily controlled via a RS232-compliant serial port, but also it has a number of commands available to control speed and acceleration allowing for optimum fluidic handling. It also has its own memory capable of storing complete subroutines that can be called and run when necessary. Control commands are issued as alphanumeric strings and combinations thereof.

The 10-position selector valve can accommodate several reagents and auxiliary devices such as minicolumns or mixing coils, allowing for the implementation of several methods simultaneously. It is also controlled via a RS232 serial port by means of simple commands such as "GO9" (i.e., "go to position No. 9").

The photometric detector was designed around a tricolour LED comprising red, green and blue components, and a silicon photodiode as detector. Each LED component was fed by a constant current source. The intensity of the DC current was adjusted by means of a "trimpot" 10-turn potentiometer to a value such that, when water was filling the flow cell, the output signal of the analogue amplifier was 


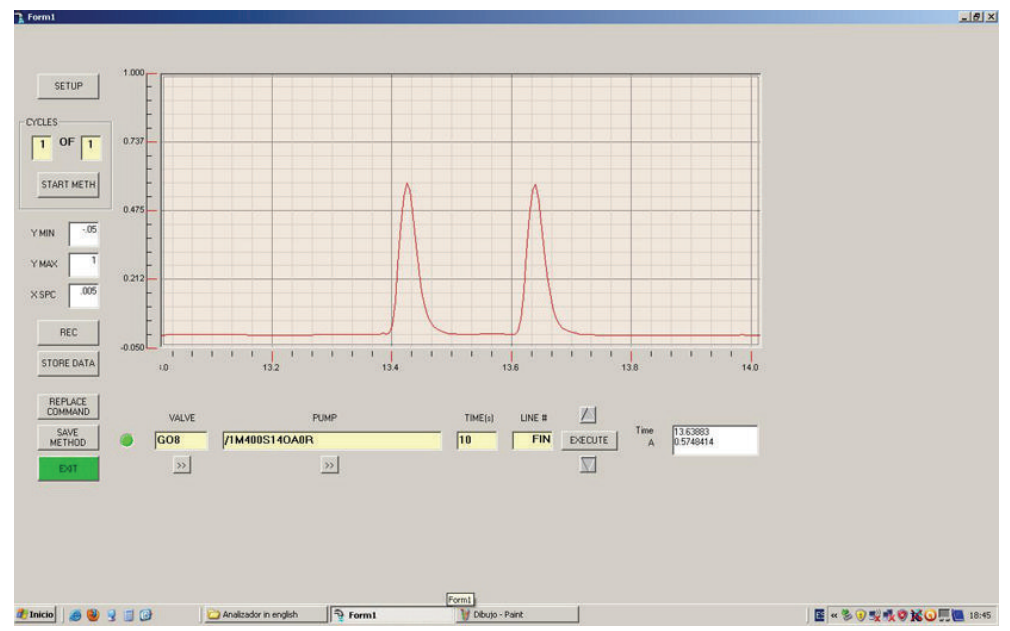

FIGURE 4: Main screen of the program.

about $70 \%$ of the saturation voltage. Given the high gain of the amplifier, the value of this current was around $1 \mathrm{~mA}$ for each LED. The use of low currents was chosen to avoid the overheating of the semiconductor and the consequent variations in light output.

The program was a critical component as the whole operation of the instrument relied on it. Also, the desired flexibility depended heavily on its correct design.

Visual Basic 6.0 was chosen as programming language because of the previous experience of the group with this language. The use of the Softwire graphic programming environment (in some way reminiscent of the LabView language) was decided because it greatly simplifies programming providing a graphic environment based on Activex controls, while simultaneously keeping the possibility of command-based programming of Visual Basic.

The program designed has two modules presented on the screen as formularies: the Operating (Main) form (Figure 4) and the Setup form (Figure 5). The first one has several command buttons and a scrolling screen simulating a stripchart recorder, where real-time data is plotted.

The Setup form allows selecting a method from those stored on hard disk. It also allows calling service routines such as initialisation of the syringe pump and selection of the serial port (COM1 or COM2) to be connected to the pump and to the valve. It also allows the selection of the A/D board and channel numbers, sampling rate, scale, as well as data paths and file names. Other functions currently available (but not essential for the operation) include the possibility of manually turning individual LEDs on or off and manually setting the photometric scale.

The methods are in fact "scripts" stored as text files. These files can be easily generated by any text editor such as Windows Notepad. The first line indicates the LED to be used. After that, each line consists of three parts: a command for the selector valve, a command for the syringe pump, and a third part containing time intervals which may be necessary to wait. Once loaded from the Setup screen, they are ready to run.
The commands for both pump and valve are simple ASCII strings. Since the analyser was to be programmed and operated by trained personnel, no effort was made to use a "natural language" which would require an interpreter increasing the complexity of the program. In fact, the set of alphanumeric commands necessary to operate the valve and the pump is small and easy to learn by the user. These commands are provided by the manufacturers in the respective manuals and are as simple as "GO9" to send the valve to position 9, "D1500R" to dispense a volume equivalent of 1500 steps of the syringe pump, and so forth.

The first active line of a method stores the LED number (1 to 3) allowing for selection of the LED with the appropriate wavelength for the intended method. Once the method is loaded and started by means of a command button on the Operation Form, each line is parsed into its three components. First, a valve command is issued via the corresponding serial COM port, sending the selector valve to a given position. Then, after waiting a fixed time period of $400 \mathrm{~ms}$ (configurable from the Setup screen), the pump command is issued via the second serial COM port. Then, if necessary, the system waits for the specified time interval before executing the next line of the script. The current valve and pump commands, time interval, and line number are shown on the screen. This screen also supports limited edition capabilities, allowing "on the fly" modifications of the script to be tested and stored. This feature turned out to be useful during methods development.

Data acquisition runs as a separate process, which can be started/stopped at any time by command buttons on the Operation screen. The program triggers A/D conversions from the $\mathrm{A} / \mathrm{D}$ interface as required. In order to be able to acquire real-time data, the system requires that the photometric (transmittance) scale be defined in advance. This is done at the beginning of the cycle while pumping water through the flow cell. The program first measures and memorises the "dark response" with all LEDs off. Then it turns the selected LED on and measures and memorises the " $100 \%$ " response. With these data stored, the program can 


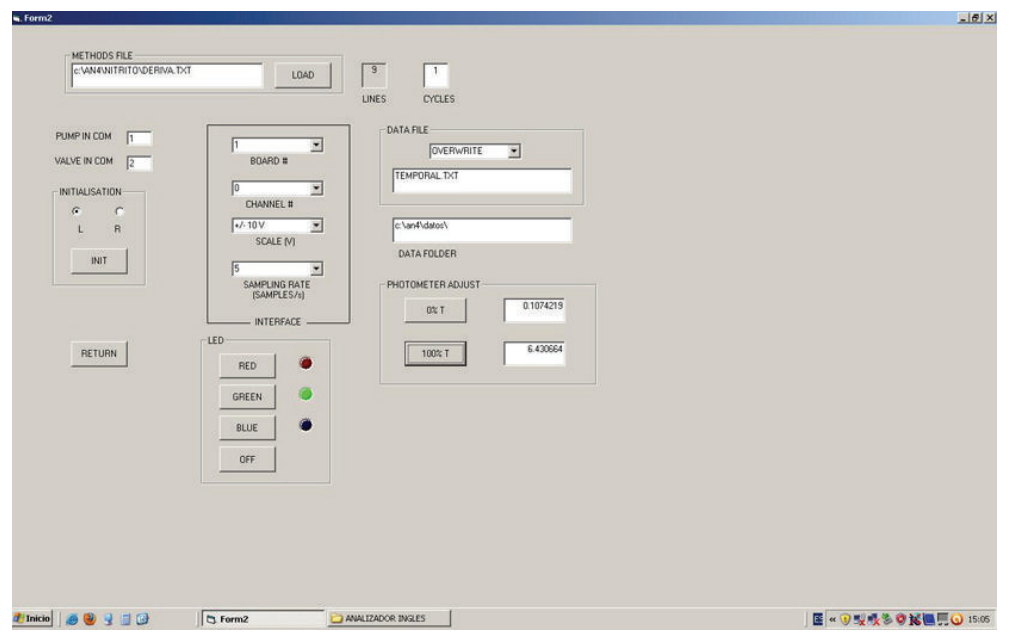

FIGURE 5: Setup screen of the program.

then calculate the absorbance each time the A/D interface is triggered. Absorbance values are then plotted on the scrolling screen and saved to a raw-data file in ASCII format for later processing.

After finishing a run, the user can choose to keep the raw-data file with a new name or to delete it. In the first case, the routine creates a new text file containing a header with information to make it compatible with the Peak Simple chromatography program. This information includes the number of data points and the sampling rate used by the $A / D$ interface, allowing for the establishment of a real-time scale in the Peak Simple program.

At this stage of the project, the use of a commercial chromatography program for data processing and evaluation was preferred in order to save development time. However, it is possible for future versions of the software to provide new routines for data processing such as the establishment of baselines, calculation of peak heights, areas and widths, handling of calibration curves, and so forth.

3.2. Cost. The system price was kept at a minimum, the syringe pump and selector valve being the most expensive items (about US $\$ 3000$ for both) followed by the notebook computer (purchased locally for US \$600). The cost of the rest of the components, mainly electronics and hardware (including the A/D interface), was under US \$1000.

3.3. Analytical Results. In order to assess the system's capabilities, several methods, based on the well-established APHA standard methods [1], were implemented and tested for each analyte. Determination of chloride, nitrite, and nitrate were implemented. Chloride was determined by the colorimetric mercuric thiocyanate method (based on APHA method 4500- $\mathrm{Cl}^{-} \mathrm{G}$ [21]), using the blue LED for detection. Nitrite was determined using the green LED by reaction with $\mathrm{N}$-(1-naphtyl)-ethylenediamine dihydrochloride and sulphanilamide (based on APHA method 4500$\left.\mathrm{NO}_{2}{ }^{-} \mathrm{B}[22]\right)$. Similarly the method of online reduction in a cadmium minicolumn and determination as nitrite (based

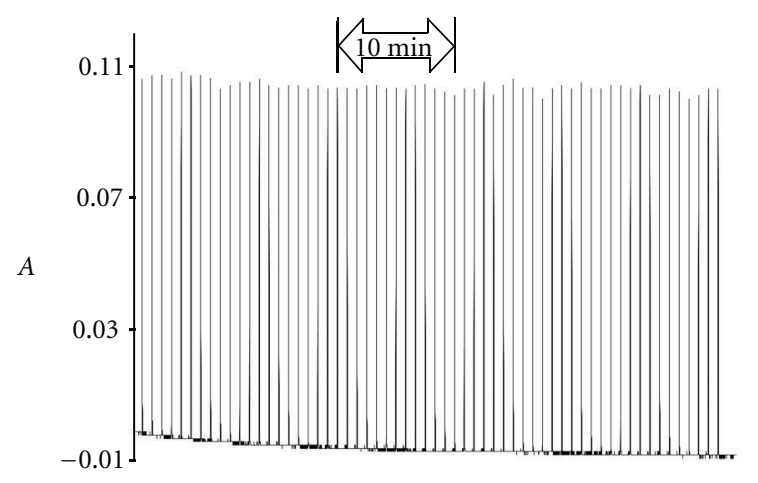

Figure 6: Stability plot of a typical 60-minute run with repeated injections of nitrite $\left(0.60 \mathrm{mg} \mathrm{L}^{-1}\right)$.

on APHA method 4500- $\mathrm{NO}_{3}{ }^{-} \mathrm{E}$ [23]) was used for nitrate. The latter APHA methods, in their batch form, were used as reference methods for validation, while for chloride, the argentometric method APHA $4500-\mathrm{Cl}^{-} \mathrm{B}$ was used. Table 1 shows the analytical figures of merit of the methods as obtained in the validation stage.

For each method, special attention was given to mediumterm stability, as there is the possibility of drift from electronic components and temperature changes in the flow cell, especially as components temperature raises during operation. For this purpose, repeated injections were carried out for a period of 60 minutes, at concentrations of $30 \mathrm{mg}$ $\mathrm{L}^{-1}$ (chloride), $0.60 \mathrm{mg} \mathrm{L}^{-1}$ (nitrite), and $10 \mathrm{mg} \mathrm{L}^{-1}$ (nitrate). The stability of both the baseline and response were assessed. Baseline drift was under 0.010 (absorbance), and sensitivity drift (measured as the relative difference of the average of the height of the first 5 peaks and of the last 5 ones) was $1.9 \%$ (chloride), $0.55 \%$ (nitrite), and 3.9\% (nitrate). Only in the latter case there was a clear trend observed in the envelope of the peaks. Figure 6 shows a typical plot of 60 minutes of repeated injections of nitrite. The slight baseline drift has 
TABLE 1: Analytical figures of merit for the automated methods developed for chloride, nitrite, and nitrate in water samples. LD, LQ: detection $(3 \sigma)$ and quantification $(10 \sigma)$ limits. Precision was measured as repeatability $(n=10)$.

\begin{tabular}{|c|c|c|c|c|c|c|}
\hline $\begin{array}{l}\text { Analyte/Figure of } \\
\text { merit }\end{array}$ & $\begin{array}{c}\mathrm{LD} \\
\left(\mu \mathrm{g} \mathrm{L}^{-1}\right)\end{array}$ & $\begin{array}{c}\mathrm{LQ} \\
\left(\mu \mathrm{g} \mathrm{L}^{-1}\right)\end{array}$ & $\begin{array}{l}\text { Linear range } \\
\left(\mu \mathrm{g} \mathrm{L}^{-1}\right)\end{array}$ & $\begin{array}{l}\text { Precision } s_{r} \\
\quad(\%)\end{array}$ & $\begin{array}{l}\text { Difference with } \\
\text { reference method (\%) }\end{array}$ & $\begin{array}{c}\text { Sampling rate } \\
\left(\text { hour }^{-1}\right)\end{array}$ \\
\hline Chloride & 0.6 & 1.90 & $1.9-54$ & 1.4 & 2.0 & 60 \\
\hline Nitrite & 0.02 & 0.076 & $0.11-3.8$ & 2.9 & -2.8 & 60 \\
\hline Nitrate & 0.5 & 1.6 & $1.6-54$ & 2.4 & -0.3 & 20 \\
\hline
\end{tabular}

no effect as the program used for data processing allows for baseline correction.

The number of methods that could be simultaneously run depends on the number of ports in the selector valve. With the 10-position selector valve used and depending on the complexity of the method, it was possible to determine up to 4 analytes sequentially without changing reagents or flow configuration. In order to determine a greater number of simultaneous parameters, it would be necessary to use a selector valve with a higher number of ports. These are currently available in the market.

One apparent limitation of the system resides in the use of a tricolour LED which limits the number of wavelengths available. However, the system can be used to implement a number of methods involving colorimetric detection, as long as the wavelength required by the method is close to one of the wavelengths emitted by the RGB LED. Depending on the difference of wavelengths, some loss of sensitivity may be expected if compared to the ideal situation of a perfect wavelength match; however, this will not necessarily diminish the usefulness of the system for the intended purpose, as demonstrated by the three methods tested in this work.

The use of an autosampler is convenient for handling large number of samples. A lab-made autosampler has been designed and is being built at this time. However, a commercial autosampler could conceivably be added to the system with slight modifications in the software allowing for serial communications with the device.

Further modifications of the system, beside those previously mentioned, would be mainly based on modifications of the software and thus easily implemented. Some of these modifications, currently under study, include allowing LED operations at any method line, allowing a more complex scheme such as using two LEDs for background correction by the two-wavelength technique, or periodically resetting the photometric scale, in order to minimise the effects of drift in the zero signal or in the LEDs emission intensity.

\section{Conclusions}

The prototype of the analyser proved to be stable and reliable. The total cost was low enough to make it affordable to a low-budget University laboratory. The analytical figures of merit found for the methods tested were satisfactory for the intended purpose. The SIA based system allowed to attain high levels of precision. The analyser presents potential for future growth and enhancements.

\section{Acknowledgments}

Financial support from the University's Commission for Scientific Research (CSIC) (research grant) and from Basic Sciences Development Program (PEDECIBA) (partial financial support) are gratefully acknowledged. The authors also thank Prof. Dr. Boaventura F. Reis (CENA, University of São Paulo, Brazil) for useful discussion concerning the design of the photometric detector.

\section{References}

[1] L. Clesceri, A. Greenberg, and A. Eaton, Standard Methods for the Examination of Water and Wastewater, American Public Health Association, Washington DC, USA, 20th edition, 1998.

[2] M. Miró, J. M. Estela, and V. Cerdà, "Application of flowing stream techniques to water analysis - part I: ionic species: dissolved inorganic carbon, nutrients and related compounds," Talanta, vol. 60, no. 5, pp. 867-886, 2003.

[3] M. Miró, J. M. Estela, and V. Cerdà, "Application of flowingstream techniques to water analysis-part II: general quality parameters and anionic compounds: halogenated, sulphur and metalloid species," Talanta, vol. 62, no. 1, pp. 1-15, 2004.

[4] M. Miró, J. M. Estela, and V. Cerdà, "Application of flowing stream techniques to water analysis-part III: metal ions: alkaline and alkaline-earth metals, elemental and harmful transition metals, and multielemental analysis," Talanta, vol. 63, no. 2, pp. 201-223, 2004.

[5] A. J. Lyddy-Meaney, P. S. Ellis, P. J. Worsfold, E. C. V. Butler, and I. D. McKelvie, "A compact flow injection analysis system for surface mapping of phosphate in marine waters," Talanta, vol. 58, no. 6, pp. 1043-1053, 2002.

[6] P. C. F. C. Gardolinski, A. R. J. David, and P. J. Worsfold, "Miniature flow injection analyser for laboratory, shipboard and in situ monitoring of nitrate in estuarine and coastal waters," Talanta, vol. 58, no. 6, pp. 1015-1027, 2002.

[7] S. Hirata, S. Karthikeyan, and T. Kajiya, "Portable flowInjection analyzer for nitrite and nitrate in natural water," Analytical Sciences, vol. 20, no. 3, pp. 567-569, 2004.

[8] B. S. Gentle, P. S. Ellis, P. A. Faber, M. R. Grace, and I. D. McKelvie, "A compact portable flow analysis system for the rapid determination of total phosphorus in estuarine and marine waters," Analytica Chimica Acta, vol. 674, no. 2, pp. 117-122, 2010.

[9] P. J. Worsfold, E. P. Achterberg, A. R. Bowie et al., "Integrated luminometer for the determination of trace metals in seawater using fluorescence, phosphorescence and chemiluminescence detection," Journal of Automated Methods and Management in Chemistry, vol. 24, no. 2, pp. 41-47, 2002.

[10] J. Tschmelak, G. Proll, J. Riedt et al., "Automated Water Analyser Computer Supported System (AWACSS)—part I: 
project objectives, basic technology, immunoassay development, software design and networking," Biosensors and Bioelectronics, vol. 20, no. 8, pp. 1499-1508, 2005.

[11] J. Tschmelak, G. Proll, J. Riedt et al., "Automated Water Analyser Computer Supported System (AWACSS)—part II: intelligent, remote-controlled, cost-effective, on-line, watermonitoring measurement system," Biosensors and Bioelectronics, vol. 20, no. 8, pp. 1509-1519, 2005.

[12] J. Ruzicka and G. D. Marshall, "Sequential injection: a new concept for chemical sensors, process analysis and laboratory assays," Analytica Chimica Acta, vol. 237, no. 2, pp. 329-343, 1990.

[13] C. E. Lenehan, N. W. Barnett, and S. W. Lewis, "Sequential injection analysis," Analyst, vol. 127, no. 8, pp. 997-1020, 2002.

[14] E. F. Schubert, Light-Emitting Diodes, Cambridge University Press, Cambridge, UK, 2003.

[15] P. K. Dasgupta, H. S. Bellamy, H. Liu et al., "Light emitting diode based flow-through optical absorption detectors," Talanta, vol. 40, no. 1, pp. 53-74, 1993.

[16] Y. Suzuki, H. Hori, M. Iwatsuki, and T. Yamane, "A fourwavelength channel absorbance detector with a light emitting diode-fiber optics assembly for simplifying the flow-injection analysis system," Analytical Sciences, vol. 19, no. 7, pp. 1025$1028,2003$.

[17] A. Fonseca and I. M. Raimundo Jr., "A multichannel photometer based on an array of light emitting diodes for use in multivariate calibration," Analytica Chimica Acta, vol. 522, no. 2, pp. 223-229, 2004.

[18] Y. Suzuki, T. Aruga, H. Kuwahara et al., "A simple and portable colorimeter using a red-green-blue light-emitting diode and its application to the on-site determination of nitrite and iron in river-water," Analytical Sciences, vol. 20, no. 6, pp. 975-977, 2004.

[19] N. Gros, "Spectrometer with microreaction chamber and tricolour light emitting diode as a light source," Talanta, vol. 62, no. 1, pp. 143-150, 2004.

[20] M. O’Toole and D. Diamond, "Absorbance based light emitting diode optical sensors and sensing devices," Sensors, vol. 8, no. 4, pp. 2453-2479, 2008.

[21] L. Clesceri, A. Greenberg, and A. Eaton, Standard Methods for the Examination of Water and Wastewater, American Public Health Association, Washington DC, USA, 20th edition, 1998, p. 4-70.

[22] L. Clesceri, A. Greenberg, and A. Eaton, Standard Methods for the Examination of Water and Wastewater, American Public Health Association, Washington DC, USA, 20th edition, 1998, p. 4-112.

[23] L. Clesceri, A. Greenberg, and A. Eaton, Standard Methods for the Examination of Water and Wastewater, American Public Health Association, Washington DC, USA, 20th edition, 1998, p. 4-115. 


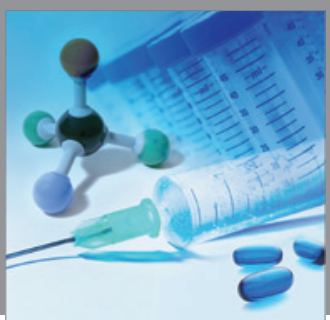

International Journal of

Medicinal Chemistry

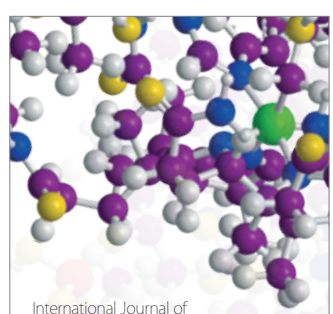

Carbohydrate Chemistry

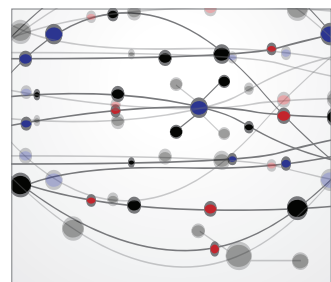

The Scientific World Journal
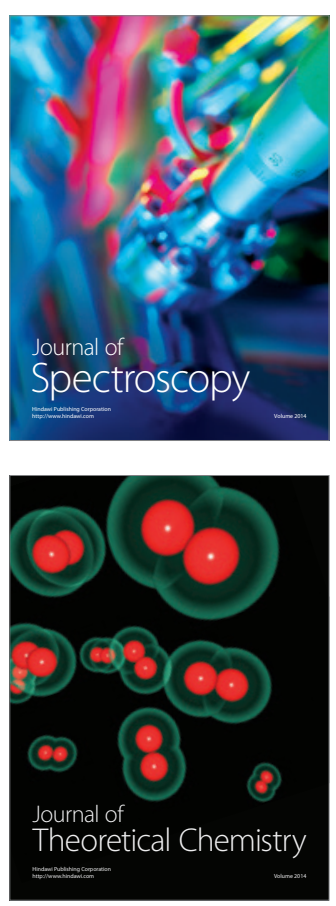
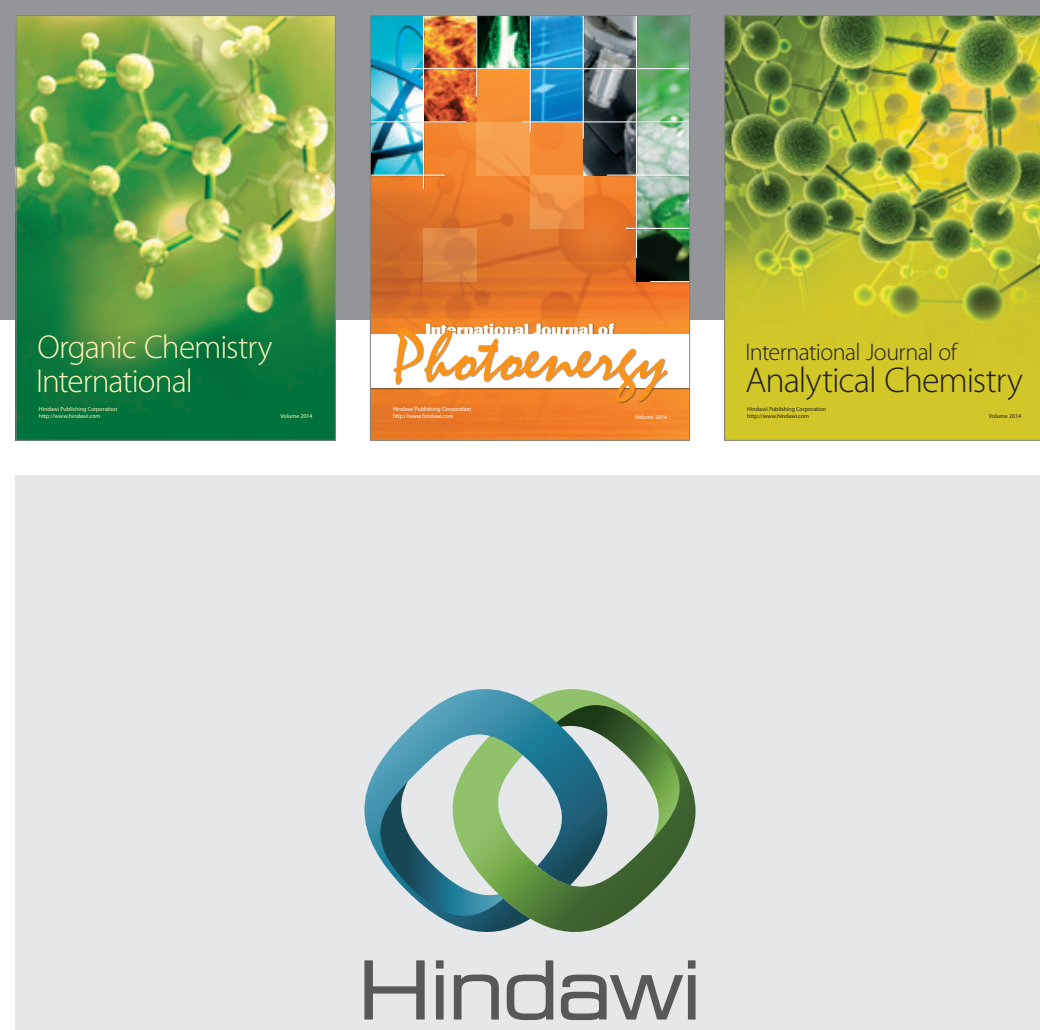

Submit your manuscripts at

http://www.hindawi.com
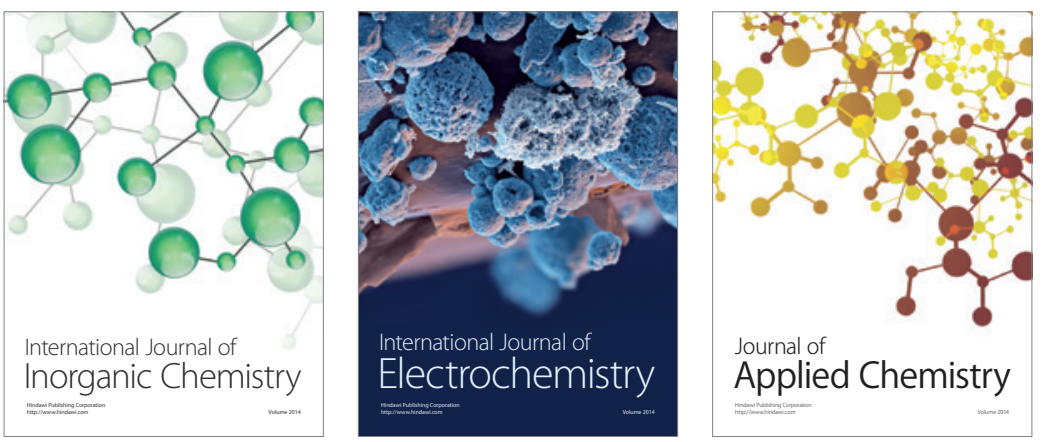

Journal of

Applied Chemistry
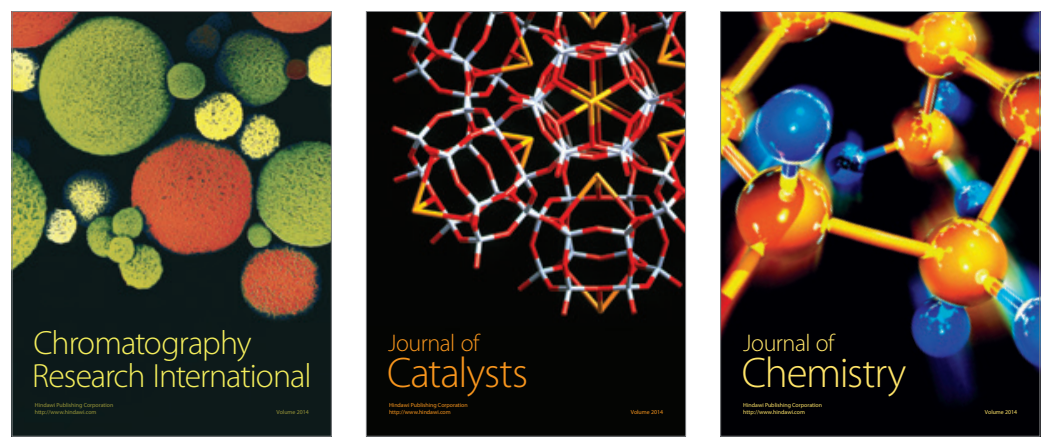
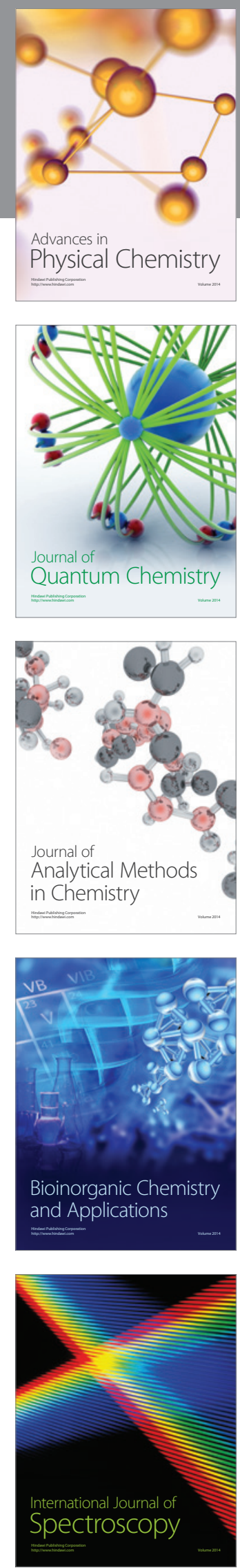